\title{
NEWTON AND WOLFF: THE LEIBNIZIAN REACTION TO THE PRINCIPIA, 1716-1763
}

\begin{abstract}
Marius Stan
ABSTRACT: Newton rested his theory of mechanics on distinct metaphysical and epistemological foundations. After Leibniz's death in 1716, the Principia ran into sharp philosophical opposition from Christian Wolff and his disciples, who sought to subvert Newton's foundations or replace them with Leibnizian ideas. In what follows, I chronicle some of the Wolffians' reactions to Newton's notion of absolute space, his dynamical laws of motion, and his general theory of gravitation. I also touch on arguments advanced by Newton's Continental followers, such as Leonhard Euler, who made novel attempts to defend his mechanical foundations against the proLeibnizian attack. This examination grants us deeper insight into the fate of Newton's mechanics on the Continent during the early eighteenth century and, more specifically, sheds needed light on the conflicts and tensions that characterized the reception of Newton's philosophy of mechanics among the Leibnizians.
\end{abstract}

When Newton's Principia appeared in 1687, it eclipsed everything else in physics for almost two decades, until figures across the Channel set out to advance its agenda or replicate some of its theorems through Leibnizian calculus. Though all praised the book's results, its underlying foundation received a mixed response, and the Leibnizians felt particularly conflicted about it. ${ }^{1}$ In thrall to Leibniz's rival program, followers were loath to switch

Marius Stan is Assistant Professor of Philosophy at Boston College. He earned his PhD from Johns Hopkins University in 2009, with a dissertation on Kant's philosophy of physics, and spent three years (2009-12) as a Mellon Postdoctoral Fellow at California Institute of Technology. His recent publications and current research focus on the foundations of classical mechanics, the reception of Newton and Leibniz during the Enlightenment, and Kant's natural philosophy.

${ }^{1}$ Outside Britain, Leibniz's doctrines reigned over the Continent in the early eighteenth century: Leibnizian natural philosophy and the Leibnizian calculus had an influential presence in Germany (through Wolff), in Italy (through Jakob Hermann and Nicholas Bernoulli), in Holland (through Johan Bernoulli and 's Gravesande), in Russia (through G. B. Bilfinger and other Leibnizians at the Imperial Academy of Science in St. Petersburg), and, eventually, in 
sides, especially after the rivalry over the calculus and the infamous exchange with Clarke had soured moods and hardened loyalties. Matters were complicated because Leibniz himself had made claims - about the nature of motion, inertia, force, and action - that sounded deceptively like Newton's. As a result, and broadly speaking, the Leibnizian response to Newton's philosophical basis for mechanics uneasily blended grudging respect, heated denial, and occasional false claims of kinship.

In the first half of the eighteenth century, not only were the foundations of mechanics in flux, but there was also little consensus that Newton himself had found the foundations for the entire discipline and, thus, that his program should set the agenda for the future of mechanics. Virtually no figure on the Continent before 1750 engaged in "Newtonian" mechanics self-consciously. A few historians have uncovered how challenging it was, in the early Enlightenment, to extend Newton's Second Law to dynamical situations beyond the motion of a free particle - a topic the Principia had treated admirably. ${ }^{2}$ And yet, this explanation, though historically sound, is incomplete. In order to understand fully the reasons for the slow spread of Newtonianism in Europe, we must also attend to how the Leibnizians reacted to the Principia. Their allegiance to Leibniz and their polemic encounter with the philosophical basis of Newton's magnum opus does much to explain the Continent's reluctance to embrace Newtonian mechanics fully.

There is still much we do not know about the fate of Newton's foundations for mechanics in Europe after the Leibniz-Clarke correspondence, and my goal in what follows is a rather modest one. Given space limitations, I address just a few key facets of the Leibnizian reception of the philosophical foundations for the mechanics of the Principia. In particular, I emphasize Wolff's reactions to Newton's absolute space and theory of motion, to his concept of force and dynamical laws, and to the notion of action-at-a-distance at play in his gravitation theory. In broad outline, the picture that emerges from my investigation here is one of acute but fruitful strife. Wolff and his disciples spell out a philosophical foundation for dynamics that was both complex and clearly indebted to Leibniz. With this basis in place, in some instances, they question the grounding of Newton's theory, and in others, they seek to appropriate those elements of Newton's program of mechanics that, in their view, had shown promise but were far from inevitable, precisely because they were not philosophically well grounded.

France (due to Malebranche, Madame du Châtelet, and the young d'Alembert). For Leibniz's influence in Italy, see Robinet 1991. For his influence in France, see Droysen 1909, Guerlac 1981, and also Barber 1955, which is an older study of Leibniz's impact in France until 1760 but is restricted to Leibnizian metaphysics.

${ }^{2}$ See Maltese 1992 and Cannon and Dostrovsky 1981. 
In section 1, after recounting Newton's case for absolute space from the nature of true motion, I offer an instance of the Wolffians' challenge to Newton's foundations by looking at their attempts to articulate a relationist theory of motion that does not need Newtonian absolute space to support it. In section 2, I turn to Wolff's attempt to colonize the Principia precisely by connecting his two a priori dynamical laws, whose original source is Leibniz, with Newton's laws. Finally, in section 3, I examine the Wolffians' fierce reaction to the proposal that Newtonian gravity may be real action-at-adistance, a proposal they denounce as inconceivable and contrary to the nature of body. Throughout these sections, I also briefly touch on the counterarguments from Newton's Continental defenders, such as Euler and Daniel Bernoulli, who, under pressure from the Wolffian critiques, restated the case for specifically Nerotonian mechanical foundations. Their arguments grant further insight into the philosophical tensions in the Wolffian treatment of the Principia's foundations. And as I suggest at the end, this episode in the reception of Newton's philosophy of mechanics also grants an important perspective on the role of philosophy at moments of scientific theory change.

\section{A HOUSE BUILT ON SAND}

Newton anchored dynamics in a view of space as an entity that is rigid, immobile, and distinct from matter, or absolute. His key motivation was that absolute space is needed to support a concept of true motion. Leibniz thought he could block that move by pointing to consequences he deemed unacceptable, namely, that bodies would have undetectable velocities and that they could move without any kinematic change relative to other bodies. Leibniz accepted that bodies have true motions but asserted that these must consist in, and hence be analyzed as, a special type of motion relative to other bodies, not to space itself. ${ }^{3}$ Yet Leibniz seems to have missed that Newton had shown in the Principia why this account of true motion as relational was impossible. Newton's case is worth revisiting, in order to see what the Leibnizians made of it.

The argument is made in the Scholium to the Definitions, where he famously presents his notions of absolute, true, and mathematical space, time, and motion. ${ }^{4}$ There, Newton takes for granted that each body has a true state of motion, understood as a complete predicate or monadic property: a body either truly moves or truly rests but not both. Newton thinks

\footnotetext{
3 Thus Leibniz in his Fifth Letter to Clarke claims: "I grant there is a difference between an absolute true motion of a body, and a mere relative change of its situation with respect to another body" (Alexander 1970, 74; emphasis added).

${ }^{4}$ In my account of Newton's argument, I follow Rynasiewicz 1995, who carefully spells out the assumptions behind Newton's thought that bodies have true motions.
} 
the assumption needs no defense - the two sides in the Copernican controversy accepted it, and the Law of Inertia assumes it. ${ }^{5}$ However, a crucial question arises now: how are we to define true motion? In what does it consist? To answer this question, Newton claimed first that true motion has certain "properties, causes, and effects" $(1999,412)$. For instance, a property of true rest is that "bodies truly at rest are at rest in relation to one another." Likewise, the effects of true motion are "the forces of receding from the axis of circular motion" (412). Now a body's true motion, he reasons, could only consist in one of two things: either relative motion, namely, some special type of kinematic change relative to other bodies; or absolute motion, that is, change of place in absolute space. In paragraphs 8 to 13 of his Scholium, Newton shows that relative motion fails to have the properties, causes, and effects that characterize true motion. For instance, relative motion fails to exhibit the causes of true motion: the latter changes just in case we apply a force to the body itself; but we could change its relative motion by impressing a force on the body's material reference frame. Hence, true motion cannot be defined as relative motion (definiri nequit), for it does not consist in (minime consistit) a change of relation to other bodies: true motion cannot possibly be relative motion. In contrast, absolute motion does have the properties, causes, and effects of true motion. For instance, bodies at rest in absolute space are likewise at rest with respect to each other. Ergo, each body's true motion consists in change of its absolute place, namely, its motion in absolute space.

It is unclear to what extent Leibniz grasped Newton's case for absolute space from the nature of true motion. In any event, Clarke was about to make him face up to it: seizing on Leibniz's admission that each body has an "absolute true motion," Clarke pointed out that Leibniz "must necessarily infer that space is really a quite different thing from the situation or order of bodies" (in Alexander 1970, 105). As Clarke saw it, Newton had proven the inference from true motion to absolute space in the Scholium to the Definitions, which he explicitly mentions in section 53 of his Fifth Letter to Leibniz (105). Unfortunately, Leibniz died before he could answer, but some disciples presumed to respond on his behalf. For instance, L. Ph. Thümmig, a protégé

${ }^{5}$ In early modern contexts, true motion was opposed to apparent motion, or the ways in which bodies appear to us on earth to move. Clearly, there would have been no Copernican controversy about apparent motion: the Earth appears to rest, and the Sun appears to move; res ipsa loquitur. Likewise for the Law of Inertia, if taken to be about merely apparent motions, it fails trivially. At issue was, obviously, the true motion (or rest) of the Earth, Sun, and unaccelerated bodies. Some called this true motion, "philosophical motion" (Descartes), "real and physical motion" (Borelli) or "proper motion" (Mariotte). See Descartes 1983, 50-52; Borelli 1667, 3; Mariotte 1740, 3. See the contribution by Andrew Janiak in this volume for discussion of how the distinction between true and apparent motion relates to Newton's theological views. 
of Wolff, wrote a sixth letter "in favor of Mr. Leibniz." ${ }^{\text {In }}$ In response to Clarke's point above, Thümmig complains:

[Clarke] ought to have proved that, from the difference between absolute and relative motion, it follows necessarily that space is entirely distinct from the situation and order of bodies - for not everyone will assent to that inference. (Sharpe 1744, 26; my translation)

Thümmig fails to see that granting "absolute," that is, true, motion necessarily entails absolute space as that with respect to which true motion is correctly defined. His mentor Wolff, reviewing anonymously the Leibniz-Clarke exchange in 1717, did no better. He saw Leibniz's claim that we acquire our idea of space by considering "solely the situations of things relative to each other" as being enough to settle the ontology of space, and he claimed that "there is no need for the reality" of space distinct from body ([Wolff] 1717, 445). ${ }^{7}$ Apparently, he too missed the force of Newton's kinematico-dynamical case for absolute space.

And yet, Wolff too sought to provide metaphysical foundations for an inertial mechanics, although his concept of force differs significantly from Newton's. In order for such a metaphysical foundation to properly ground physical theory, Wolff is required to give a theory of motion, that is, a principled definition of the concept of motion presupposed by the Law of Inertia and the laws of his Leibnizian dynamics. Wolff is evasive on this count and does not seem fully aware of his obligation. That is, unlike Newton, he appears to miss that his metaphysics of space must be rendered compatible with his theory of mechanics, via a concept of true motion. In his Philosophia prima, sive Ontologia, Wolff defines motion as a "continual change of place," which he construes as change in the "order of coexistence," that is, a change in the array of relative distances and angles between simultaneous actual bodies (1730, secs. 642-44). Because Wolff denies absolute space, he must be taking all motion to be relative. During the early modern period, "relative motion" was fundamentally ambiguous: for some, it meant relationism; for others, it meant relativism. Relationism is the view that each body does have a true motion, which allegedly consists in changes in kinematic relations to other bodies. Relativism is the blanket denial of true motion, that is, the view that there is no fact of the matter as to whether a body really moves or is stationary. Thus, relationism and relativism are logically incompatible. ${ }^{8}$

\footnotetext{
${ }^{6}$ Gregory Sharpe replied to this letter in 1744, after Clarke's demise (see Sharpe 1744).

7 'Wolf' is in square brackets because he published the review I refer to anonymously, although now we know with certainty that he was its real author.

${ }^{8}$ Rynasiewicz (2000) first points out this fundamental ambiguity and explains how it affects
} 
Wolff does little to help the reader decide how he means "the relativity of motion." His gloss suggests that he might endorse relationism, not relativism: "if A, B, C, D are some coexistents whose order of coexisting changes, and the reason for the change is in $\mathrm{A}$, then A moves whereas $\mathrm{B}, \mathrm{C}$ and $\mathrm{D}$ rest" (Wolff 1730, sec. 643). Hence, it seems, we may take the "reason for the change" in a body's distance relative to other bodies as a criterion of its true motionwhich entails relationism. But Wolff's ideas on what counts as a reason for such change remain equivocal. On the one hand, he offers, in an example, an applied force as the reason for changes in distance. ${ }^{9}$ On this construal, a body moves truly just in case a force accelerates it. It is still unclear what the quantity of this true motion is. It could be change in momentum $\Delta(\mathrm{mv})$ or change in vis viva $\Delta\left(\mathrm{mv}^{2}\right)$; his dynamics allows both. ${ }^{10}$ These choices pull in different directions; the former is Galilean-invariant, the latter presupposes a distinguished inertial frame, or standard of rest. On the other hand, Wolff's rationalist "cosmology," presented in his Cosmologia Generalis (1737), entails that a reason for a body's motion relative to other bodies may be its endogenous vis motrix - or active force - "consisting in a continual endeavor to change place" (sec. 149). From this, it follows that a body in inertial translation has a force whereby it changes true place, ergo moves truly. This likewise requires Wolff to admit a distinguished material frame, relative to which bodies have true velocities - and so requires Wolff to endorse relationism, not relativism.

Key parts of Wolff's system push him toward the relationist option. "There is nothing real about motion but the endeavor [conatus] whereby a mobile strives to change its place," he says and then explicates that endeavor as being determined by the mobile's "celerity and direction" (Wolff 1737, sec. 173). In fact, Wolff's mechanics rests essentially - more so than Newton's - on a concept of true velocity: bodies play different dynamical roles in interactions, depending on whether they truly move or truly rest (I explain this point more fully in the next section). So Wolff's mechanics, whether he knows it or not, crucially rests on a version of relationism: bodies have true velocities relative to a single, global frame of reference, marked off by some privileged bodies or matter. Regrettably, he never tries to explain what that frame is; a fleeting reference to the fixed stars is not enough to credit him with that view, nor would it be tenable after 1718, when Halley finds that the stars have proper

our understanding of early modern figures who opposed Newton on the issue of the relativity of motion.

9 This is the gist of his unhelpful example of four balls, A, B, C, D, at relative rest, with a hypothetical "Titius" subsequently pushing A. Ergo, A is in motion, he concludes; see Wolff 1730 , sec. 643 .

${ }^{10}$ He has two measures of force, impetus and vis viva (see Wolff 1737, secs. 420-27, 478-81). 
motions. ${ }^{11}$ Wolff's many disciples and sympathizers - Stiebritz, Thümmig, Gottsched, Reusch, Hanov, Burkhäuser, Winkler - repeat his mantras about the nature of motion, force, and the absence of absolute space, strongly implying their own adherence to true motion as being relative to some special bodies. $^{12}$

Unexpectedly, this confident group is soon forced into a defensive mode. Euler, who had been waging war on post-Leibnizian monadologies for some years, takes aim at their theory of motion in "Réfléctions sur l'Espace et le Tems" (1748). ${ }^{13}$ He argues in particular that the Wolffians' relationism is unable to ground the Law of Inertia and urges them to adopt absolute space instead. Euler sees the Law of Inertia as a conjunction of two claims: that a body at rest "in some place without motion will ever remain in it unless expelled by some external force" and that all bodies are governed by the "conservation of uniform motion in the same direction" (Euler 1748, secs. 6, 17). He starts with the case of rest and notes that, sans absolute space, Wolffians must analyze "remaining in the same place" as "keeping the same distance relative to some special bodies." A Wolffian, he alleges, has two ways to construe the body's equilocality: as either (1) keeping the same "relation with respect to other bodies that surround it" or (2) "with respect to the fixed stars" (secs. 7, 11).

Euler attacks both of these claims and shows that they allow violations of the Law of Inertia. His refutation of (1) is especially powerful. Let a body A, Euler supposes, "keep itself in the same neighborhood of bodies B, C, D, E." 14 (Call this neighborhood the privileged frame.) Now accelerate the frame. Predictably, A's distance relative to B, C, D, E changes. As a result, a Wolffian must conclude that the body has truly moved: because A's true motion just is a

${ }^{11}$ Wolff remarks that "Astronomers gather the motions of planets and comets as they refer them to the fixed stars, which, from other, previous observations, they know not to have changed their places" (Wolff 1730, sec. 644). Recall that, in Wolff's account, a body A moves (truly) relative to a set B, C, D only if B, C, D keep their relative distances unchanged. In 1718, Halley announced that "the three Stars Palilicium or the Bulls Eye, Sirius and Arcturus ... are found to be above half a degree more Southerly at this time than the Ancients reckoned them." That is to say, they have slowly changed their distances relative to the other stars, hence are not really fixed, and so cannot be immobile. See Halley 1720, 736-38.

12 See, e.g., Gottsched 1733, secs. 136, 182, 327, 349-51; Thümmig 1735, vol. 1, ch. 2, secs. 30-42; Winckler 1735, secs. 684-85; Stiebritz 1744, secs. 302-09; Hanov 1762, secs. 2-7; and Burkhäuser 1771, secs. 624-32. More details on their position are in Stan, forthcoming, sec. 2.4. On the evolution of the Wolffian school, see Mühlpfordt 1986.

${ }^{13}$ Calinger (1969) explores Euler's polemic with monadological metaphysics during the 1740s.

${ }^{14}$ Euler's example is a body A floating in still water, with B, C, D, E being four quiescent particles of water as A floats in it. He runs a thought experiment in which he sets the water flowing. The predictable outcome is that, at first, A will lag behind B, C, D, E for a short while, until the flowing water entrains body A with it, such that eventually A comes again to rest (though at a greater distance) relative to $\mathrm{B}, \mathrm{C}, \mathrm{D}, \mathrm{E}$. 
change of distance relative to $\mathrm{B}, \mathrm{C}, \mathrm{D}, \mathrm{E}$, whenever such change occurs, the body's true motion changes ipso facto. But, as Euler points out, on this account, the body violates the Law of Inertia: it has changed from rest to motion yet no force was applied to it. Further, to keep A at rest relative to B, C, D, E (after the frame has been accelerated), a force needs to be applied to A. Now the Wolffian description of this process must be as follows: A was at rest, and it stayed at rest. Once again, Euler points out, this construal has the body violating the Law of Inertia: a force was applied to the body, and yet it did not change its state of motion. ${ }^{15}$ But the Law of Inertia is true: it is "so solidly established that one would greatly err if one wished to doubt" its validity. Sed contra, we may "reject, in Metaphysics, all ideas and arguments, well-founded as they may seem, if they lead to conclusions contrary" to this law (Euler 1748, sec. 2). Accordingly, we must discard as false the Wolffians' idea of place and, thus, their construal of motion, or change of place. The failure of their theory of motion to justify the Law of Inertia, Euler infers, proves that "necessarily there must be some other real entity" alongside bodies: "no doubt, that would be space" (sec. 17).

What makes Euler's attack especially damaging is his charge that Wolffian relationism makes forces neither necessary nor sufficient to change a body's state of motion - flatly contradicting the Law of Inertia. Newton had made the same point himself, as part of his three-pronged case against relationism. ${ }^{16}$ His "argument from causes" was precisely the claim that if true motion is analyzed as motion relative to some special bodies, then forces are no longer necessary and sufficient to change it. "Therefore, every relative motion may be changed while the true motion is preserved, and can be preserved while the true one is changed, and thus true motion certainly does not consist in relations of this sort" (Newton 1999, 412; emphasis added). We do not know if Euler consciously took up Newton's Principia argument or just rediscovered it. Whatever the case, his statement of the charge proved unanswerable. In 1751, a stunned review in the Wolffian-friendly Nova Acta Eruditorum merely sums up his point, with no attempt to respond. That same year, a second review, in the Wolffian propaganda organ Nouvelle Bibliothèque Germanique, equally fails to give an answer. ${ }^{17}$ The Wolffians do try to engage Euler over a decade later, when F. E. Boysen, a theologian disciple of Wolff, published Réfléctions sur l'Espace along with some letters by Euler on the nature of space and time, adding some allegedly impartial comments of his own, though in

15 This argument of Euler's is strikingly analogous to Newton's critique in De Gravitatione of Descartes's relationist account of motion. Janiak (this volume) discusses that critique in detail.

16 The case is three-pronged insofar as Newton indicted relationism on three counts: it fails to vindicate the (1) properties, (2) causes, and (3) effects of true motion.

17 The review of Euler's paper is in Anonymous 1751, 75. 
fact they were overtly hostile to Euler. ${ }^{18}$ Boysen steers the debate back to metaphysical and theological arguments, but eventually, instead of answering Euler's attack, he pleads that "ineluctable circumstances" keep him from rebutting Euler's critique, promising to answer on another occasion (Euler 1763, 157). He never did keep his promise, leaving Wolff and his followers without any official reply to Euler's public charges.

Euler had aimed merely to show that the Wolffians failed to properly ground the Law of Inertia, which he took to be common to all traditions of mechanics in his time, whether Newtonian, Leibnizian, or otherwise. Inadvertently, however, his attack reverberated throughout the foundations of the Wolffians' entire project. Wolff had claimed that mechanics rests on two principles that only his metaphysics could ground: a law of inertia and a law of action and reaction. But these two laws are not quite Newton's eponymous principles, despite their surface similarities (as I detail in the following section). Wolf's laws assume that bodies have true velocities because they presuppose an objective distinction between motion and rest. So, for the grounding to succeed, it needs to connect the dynamical terms in his two laws - vis inertiae, vis motrix, actio, reactio - with the true velocities of bodies. ${ }^{19}$ Euler's critique entails that the above distinctions are untenable without absolute space - and so Wolff's vision of anchoring dynamics in metaphysics was bound to fail as long as it refused a Newtonian foundation.

\section{COLONIZING THE PRINCIPIA}

On the Continent, philosophers swayed by Leibniz articulated in detail a rationalist-metaphysical basis for his dynamics, and some sought to use it as a bridgehead from which to colonize Newton's mechanics, by appropriating some of its conceptual foundations and certain select results. Wolff is again a case in point. In his Cosmologia Generalis, he distinguishes "rules of motion," or

${ }^{18}$ See Euler 1763. The volume includes a few letters on space and time that Euler had exchanged with Georg Venzky, a theologian, philologist, and translator from Prenzlau, busily involved in correspondence with many intellectuals of his time. The collection of letters between Euler and Venzky was edited anonymously, but conclusive evidence shows the editor to be the Lutheran theologian Fr. E. Boysen (1720-1800). On Venzky, see Hirsching 1812, 255-71; on Boysen, see Döring 1831, 147-51. Proof that Boysen edited Euler's letters with a German version of Réfléctions sur l'Espace is in Döring 1831, 150, and Speiser 1960, xxxix. Venzky had translated Clarke's sermons into German; Boysen excoriated him ex post for adopting, out of sheer Anglophilia, "errors of thought" such as absolute space. See the Preface in Euler 1763.

19 The Wolffian foundations of mechanics predicate that a body in (uniform straight-line) motion is endowed with an "active force of motion," vis motrix. In contrast, bodies (truly) at rest have a mere "passive force of resistance," vis inertiae. Analogously, an action is an exercise of active force by an agent on a patient, whereas a reaction involves the patient resisting an agent, by means of its passive force. In every two-body impact, a patient is the body that is either at rest or moves more slowly than the other. I detail these aspects of Wolffian mechanics in Stan 2011. 
kinematic formulas for direct impact, from dynamical "laws of motion," which are "general principles" on which the rules rest. Those general principles, it turns out, are two: a law of inertia and a law of action and reaction. ${ }^{20}$ According to Wolff, physicists "merely assume" these laws without proof, whereas "it is the Metaphysicians' task to demonstrate them" (1737, secs. 302-03).

Taking on the task of the metaphysician, Wolff submits that "induction is not enough to evince the truth" of the two laws above, and he seeks to demonstrate them a priori (Wolff 1737, sec. 304, note). He proves piecewise a series of claims whose conjunction yields the kinematic content of the law of inertia: that only "external causes" can move a body at rest; that only these causes can change the velocity of a body moving uniformly; that a body in translation cannot come to rest unless through an external cause; and that a moving body will continue in a straight line if no obstacle impedes it (secs. 305-11). He takes the same approach to deriving his law of action and reaction. Stepwise, he proves that in any two-body collision an agent body acts on a patient, whereas the patient body reacts to the agent; that the reaction of the patient stems from its force of inertia; that no corporeal action occurs without a reaction; and that action and reaction are equal and opposite (secs. 313-19, 343, 346). Wolff's derivations start with premises that are themselves established independently of experience: metaphysical tenets about the nature of interaction, the ontology of forces associated with motion and rest, and, crucially, Leibniz's grand principe de raison, the Principle of Sufficient Reason.

Elsewhere, I have shown that Wolff's two dynamical laws ultimately come from Leibniz, via the latter's disciple Jakob Hermann (Stan, forthcoming, secs. 2-3). Wolff, therefore, spells out an ontology of body and force sufficient to provide an a priori grounding for his two Leibnizian laws. And yet, Wolff also claims that his two principles are the same as Newton's First and Third Laws, albeit restricted to action by contact, the only form of interaction admitted by Wolff. ${ }^{21}$ However, with this claim of kinship, he overreaches, for beneath the verbal surface of Wolff's two laws, a conceptual chasm separates his concepts of inertia and of action-reaction from Newton's. Namely, there are irreconcilable differences between Wolff's and Newton's dynamical laws: they rest on doctrines of force and mechanical agency fundamentally at odds with another, and they relate differently to Galilean relativity.

${ }^{20}$ Eric Watkins first drew our attention to Wolff's two laws of motion, and noted some important differences between them and Newton's eponymous laws, in his groundbreaking Watkins 1997. Here, I explore in greater depth those differences (thus confirming Watkins's sound insight), and seek to draw the right historical lesson from them.

${ }^{21}$ See, e.g., Wolff 1737, secs. 315, 350. 
Consider first Wolff's vis inertiae, which, following Leibniz, he calls a "force to resist motion." ${ }^{\prime 22}$ He means the term in three senses: his force of inertia prevents a body from self-accelerating; it makes a body at rest resist incoming bodies; and it makes a slower body resist a faster one. But when a moving body runs into a stationary body or a faster-moving body meets a slower one, it exerts a vis motrix whereby it "strives to change place" (Wolff 1737, secs. 135, 146). In Wolff's mechanics, these two forces differ in kind: force of inertia is passive, and motive force is active. It follows that bodies in one and the same inertial state - whether rest or uniform translation - exert fundamentally different (Wolffian) forces. Newton, in contrast, has no such duality in his foundations: in the Principia, the force of inertia resists changes of state, not "motion," and it maintains both rest and inertial motion, no matter how fast it moves. In this respect, Wolff's dynamical basis for the law of inertia differs crucially from Newton's. ${ }^{23}$

Just as alien to Newtonian theory is Wolff's view of action and reaction. For Wolff, action is the spending of active vis motrix by an agent body, whereas reaction is a resistance by a patient, stemming from its passive vis inertiae. These claims rest on a view of interaction as an asymmetric clash between bodies in heterogeneous dynamical roles, exerting heterogeneous forces. But in three crucial respects such a view is at odds with what is presented in the Principia. First, Newton's Third Law entails that interacting bodies are dynamically on a par, and their mutual actions are homogeneous vires impressae (impressed forces). Hence, far from supporting a distinction between agent and patient (in interactions), Newton's mechanics explodes it. Second, Newtonian actions and reactions are exogenous impressed forces, codified by the Lex Secunda. Wolff's forces are inherent in bodies as they move or rest; their measure is unclear. Finally, Wolff restricts his law of action and reaction to impact. Consequently, it does not apply to centripetal forces between distant bodies as modeled in the Principia.

Wolff's two dynamical laws and the philosophical doctrine in which he embedded them went on to become hugely influential in Germany and, to a lesser extent, in France. ${ }^{24}$ And yet neither he nor his followers ever addressed

${ }^{22}$ Leibniz had claimed that bodies have "a natural inertia which is opposed to motion," in De Ipsa Natura (1698, sec. 11). After Wolff, his disciple Hanov likewise referred to vis inertiae as the "principle that resists motion" (Hanov 1762, 2).

${ }^{23}$ Wolff also calls his vis inertiae "Kepler's force of inertia," but this is incorrect. Kepler's was a force of self-deceleration that brought moving bodies to rest; and in this sense, neither Wolff's nor Newton's respective laws of inertia are compatible with Keplerian vis inertiae.

${ }^{24}$ In Germany, various figures influenced by Wolff- e.g., Baumeister, Gottsched, Winckler, Burkhäuser, Hanov, Reusch - adopted and propagated his metaphysical dynamics; see, for details, Stan, forthcoming. Wolff's conception of force and action and reaction likewise influenced Madame du Châtelet rather strongly. Furthermore, in 1739, Thomas LeSeur and François Jacquier, two French Minims, edited Newton's Principia "with running commentaries." 
the deep tensions between their two laws (together with the dynamical notions they assume) and Newton's theory. Presumably, rigorous compatibility with Newton's mechanics was not their foremost concern. Rather, the situation suggests that once they had erected a metaphysical basis for dynamics, the Wolffians tried to colonize the Principia, seeking to appropriate from it what was acceptable to them, given their nonnegotiable philosophical commitments. This suggestion appears more likely when we realize that, for the Leibnizians, Newton's theory had outlined a mechanics that showed great skill but was far from inevitable as a general theory of mechanical processes precisely because it was not philosophically well grounded. At any rate, one thing seems clear. Wolff's embedding of force laws and action and reaction in his broadly Leibnizian ontology of body is not an effort to bridge the chasm between Leibnizian metaphysics and Newtonian mechanics. Rather, his first priority was to articulate an ontological basis for Leibnizian dynamical concepts and then use it as a home base for incursions into Newtonian territory. ${ }^{25}$

The same colonizing intent lurks behind Jakob Hermann's orbital dynamics in his Phoronomia (1716), the most important comprehensive work on particle mechanics published between Newton's Principia and Euler's Mechanica of 1736. So far, scholars have focused on Hermann's use of the Leibnizian calculus to recast select theorems on central motion from Book One of the Principia. ${ }^{26}$ But not enough attention has been paid to the physical interpretation that Hermann gives his calculus-based theorems. He embeds them in a dynamical framework that is thoroughly Leibnizian: instead of adopting Newton's concept of impressed force, Hermann sets out with Leibniz's duality of forces - active and passive, live and dead:

That which urges a body to move or from which motion results - viz. that which, if posited, corporeal motion is also posited - is called motive force (vis motrix), which we may divide into Live and Dead. . . For the sake of greater clarity, we will call Live Force simply by the name of Force, whereas Dead Force, of whatever kind it may be, shall be called Solicitation. (Hermann 1716, 2)

Against this taxonomy, Hermann goes on to recover a number of Newtonian results from the Principia in of the Phoronomia (Book One, secs. 1-2). However, he interprets these results as facts about one particular type of Leibnizian

Their glosses to Newton's concepts of vis insita, impressa, action and reaction are lifted, nearly verbatim, from the Leibnizians Jakob Hermann and Wolff. LeSeur and Jacquier mistakenly ascribe to Newton Wolff's oppositions above between active and passive force, agent and patient, action and resistance. See LeSeur and Jacquier 1739, fn. 7-9, 32. Their commented edition was reprinted in 1760 and 1822. Madame du Châtelet reprises these Wolffian oppositions in her Institutions the Physique (Du Châtelet 1742, 245).

${ }^{25}$ Thus, my analysis of Wolff's laws above confirms Watkins's original insight that "Wolff's principles have more in common with Leibniz's laws of motion" (cf. Watkins 1997, 321).

${ }^{26}$ See, e.g., Nauenberg 2010. 
"solicitation," namely, gravity. Moreover, he observes a Leibnizian stricture: his theorems are all limited to one-body orbital motion, since mutual attraction (and the two-body gravitational dynamics that supports it) was unacceptable to Leibniz and his followers. Just like Wolff, then, Hermann uses Leibnizian natural philosophy as a base from which he launches a raid into Newtonian territory, seeking to appropriate what was deemed acceptable from a distinctively Leibnizian point of view.

\section{GRAVITY'S RAINBOW}

Newton's celestial dynamics suggests the reality of action-at-a-distance, that is, that masses are genuine sources of impressed force on other masses that are separated by finite distances. The implication seems to have troubled Newton, who famously took an agnostic stance on the "mechanism" of attraction, claiming that he will not "feign hypotheses." ${ }^{\text {"27 }}$ Yet his caution was lost on Leibniz, who accused Newtonian gravity of being unintelligible and (or because) contrary "to the nature of bodies." 28 These two strands of dissent resurfaced in attacks on distant gravity after 1716. Some complained that gravity was unintelligible; others rebuked it as impossible if it meant, in Euler's erudite pidgin, wie einem attributo essentiali corporum (as an essential property of bodies). ${ }^{29}$

Wolff seems to belong in the latter camp. "Action at a distance is impossible," he declares, allegedly because "a body does not act on another unless it presses against it" (Wolff 1737, secs. 323, 321). To justify the latter claim, he relies again on his ontology of body and Leibniz's Principle of Sufficient Reason. In Wolff's doctrine, bodies are endowed with two kinds of force: if they move, they have a vis motrix sive agendi, an endogenous "striving to change place" and a capacity to displace obstacles in their path. If they rest, they have a vis inertiae sive passiva, an inherent striving "to resist motion," through which they impede the advance of another body that strikes them (secs. 130-32, 135-37). For Wolff, action is an actual exercise of motive force by a body such that it alters the inertial state of another (sec. 142). ${ }^{30}$ But, he adds, a body

\footnotetext{
${ }^{27}$ For Newton's position on distant gravity, compare Henry 2011 and Janiak 2008, 50-130. Newton's notion of gravity as a "quality" of bodies is explored in Miller 2009.

${ }^{28}$ For instance, in his Third Letter to Clarke (Alexander 1970, 30).

${ }^{29}$ See Euler's letter to Goldbach, dated 25 April 1744, in Fuss 1843, 274.

${ }^{30}$ On this topic - the link between force and action - Wolff's metaphysical mechanics slides into incoherence. Following Leibniz, Wolff does not define vis inertiae as a force of maintaining a state, as Newton had done. Instead, he ends up with a duality of forces endogenous to bodies in inertial states: vis motrix inhabits bodies in (uniform, straight-line) motion, whereas those at rest have a vis inertiae. Now, these are forces in single bodies, and Wolff claims that they act -motive force acts to make a moving body change place continually, whereas the force of inertia acts to prevent a stationary body from self-moving. This view is in blatant conflict with his tenet above
} 
never actuates its vis agendi unless "there is a reason why it should act on another body." And the only such reason, he asserts, is if inert matter lying in its path makes contact with the body, thereby preventing its advance. But if a net distance separates two bodies, each can move freely and neither obstructs the other's path; hence, "there is no reason" why one must act on the other (sec. 320). Ergo, action at a distance is impossible because it is devoid of a sufficient reason.

Ultima facie, then, Wolff really objects to Newtonian gravity because it is unintelligible. His disagreement with Newton stems from their conflicting notions of intelligibility and physical explanation. For the author of the Principia, centripetal forces are intelligible if they are "deduced from phenomena," that is, shown to be necessary and sufficient causes of Keplerian orbits. ${ }^{31}$ If they are so deduced, and generalized by induction, the forces will explain the phenomena they cause - motions in orbit (or mutual inverse-square accelerations in general). Newton thinks that centripetal forces are both intelligible and explanatory, provided they are "universally established by experiments and astronomical observations" (Newton 1999, 795). In turn, forces may have their own causes, which natural philosophy ought to uncover; but our provisional ignorance of their causes is no impediment to admitting the forces themselves as intelligible causes of motions, if they are correctly deduced from the motions. For Newton, partial explanations are still intelligible explanations. ${ }^{32}$ Wolff, in contrast, adheres to a doctrine according to which intelligibility amounts to being subject to laws or principles that are ultimately grounded - whether deductively, through concept analysis, or à la Leibniz, through the Principle of Sufficient Reason - in metaphysical facts about bodies and their attributes. Inevitably, Wolff's idea of intelligibility leads him to disagree with Newton.

Certainly, Wolff is entitled to his own views on explanation and intelligibility. But given his sharp opposition to Newton's highly successful theory of gravitation, it is fair to ask whether Wolff's position is internally coherent. Let

that body forces act only when two or more bodies collide or interact. The matter deserves more attention than I can devote to it here.

${ }^{31}$ Newton proves that a gravity-like centripetal force is a necessary cause of orbiting by means of his solution to the so-called direct Kepler problem: given an elliptical path, to find the force that produces it. Newton solves it by showing that, for a body to orbit in an ellipse, it must be acted on by a force directed toward a focus and whose strength decreases as the inverse square of the distance from the focus. This shows that the force is a necessary condition of the motion. To prove that the force is a sufficient condition, Newton solves the so-called inverse Kepler problem of orbital dynamics: to find the orbit if the force is given. Newton proves that an inverse-square centripetal force is enough to move the body in an ellipse - or, more generally, a conic, depending on its initial velocity. For a lucid account of Newton's treatment of the direct problem in the Principia, see Brackenridge 1995, 3-118.

${ }^{32}$ On Newton's conception of explanation, see Ducheyne 2011, ch. 1. 
us inspect more closely Wolff's idea of a reason: why exactly is bodily contact the exclusive reason for physical action? All physical change (including acceleration) always occurs "by motion," he claims, equivocally. ${ }^{33}$ So he infers abruptly, "no body can produce motion in another in the absence of mutual contact" (1737, sec. 70). But that is a decree, not an argument. Sensing that blunt fiat may not be enough, Wolff quickly adds, "experience too confirms [that all change is by contact], for we do not observe any mode being induced in a body except by a contiguous one" (sec. 70). ${ }^{34}$

Of course, now we have a question: from Wolff's point of view, what are we to make of manifest cases of attraction, for example, magnetism and electricity? All we are entitled to say in such cases, he declares, is that "we observe bodies approach each other until they adhere mutually," but "far be it from us" to admit real attraction being at work there - a claim for which Wolff gives no sustained argument in Cosmologia Generalis. Instead, he offers several considerations that allegedly challenge the real possibility of attraction (1737, secs. 320-23); however, each of these considerations raises serious questions for his criticism of Newtonian action-at-a-distance.

First, he asserts that the "cause" of such attractions is "not evident to the senses." However, this imposes a demand he never argues for, and so the constraint that all physical causes must be evident to the senses seems ad hoc. More alarmingly, Wolff's own cosmology fails to live up to this standard: Leibnizian ether vortices, his pet cause of planetary orbits, are just as hidden from the senses as Newtonian gravity. Moreover, he is at variance with himself: in the same book, he declares that "we attribute vis motrix" to bodies because "we experience in ourselves" their endeavor to continue in motion, for example, as we try to stop a translating body (Wolff 1737, sec. 149). But then so do we experience the magnet's attractive force as we hold a piece of iron close to it.

Second, Wolff insists that distant attraction would be casus purus, sheer indeterminacy. However, that appears to be a non sequitur. Casus purus is a term of art for him, and it denotes a property or change in some entity, A, for which "no sufficient reason is given, whether intrinsic to A or extrinsic, namely, situated in another being different from it" (1737, sec. 94). Yet

\footnotetext{
${ }^{33}$ Wolff's crucial premise is his tenet, from Ontologia (1737, sec. 667), that "in a composite being there can be no change except by motion." There, by "motion" he means both (1) a body's change of place and (2) the change of its parts' position relative to each other. The latter sense has the paradoxical outcome that one can "move" a body by a deformation that leaves its center of mass in place, i.e., by keeping the body at rest. The more serious equivocation is this. Wolff takes "by motion" to mean "all change in a body's states or properties supervenes on changes in its own state of motion or the configuration of its parts" (1737, sec. 667). But, in Cosmologia, "by motion" means "all bodily change requires contact with another body that moves."

${ }^{34}$ A mode is a basic attribute of "composite beings" or bodies. Such modes are shape, size, and "motion," i.e., its inertial state.
} 
nothing in Wolff's doctrine entails that all such "extrinsic reasons" must be contiguous to the body. Newton's theory evades his charge: for any two masses $\mathrm{A}$ and $\mathrm{B}$, if no kinematic or dynamical constraints on $\mathrm{A}$ obtain, then the presence of $\mathrm{B}$ is a sufficient reason for $\mathrm{A}$ to accelerate toward $\mathrm{B}$. It follows that, by Wolff's own criteria, Newtonian gravity must count as intelligible.

Third, he objects that we are "incapable of proving" that real attraction without contact exists. However, this complaint is opaque, hence, difficult to assess. Perhaps Wolff charges here that the defenders of attraction cannot prove their kinematic laws (about gravitational accelerations) as he requires, namely, by deductive derivation from a priori dynamical laws. ${ }^{35}$ But that seems rash. Newton did prove by "deduction from phenomena" that gravitation is the necessary and sufficient condition for the Keplerian motion of the planets around primary bodies. Then by the law of action and reaction - which Wolff mentions in Cosmologia Generalis and claims is a priori-Newton inferred that gravitational attraction must be mutual in any two-body orbiting system. Not least, Wolff's objection appears to be self-defeating, as soon as we note that in his account of impact (the very paradigm of physical action, in his doctrine), Wolff himself fails to live up to this requirement: though he claims that the laws of impact are provable a priori from his two metaphysical laws, he never carries out an actual derivation, nor it is clear that he can do so.

Lastly, Wolff asserts that we cannot understand how two distant bodies can approach mutually unless some other, contiguous matter propels them toward each other, "as recent Physicists, following Descartes, are wont" to claim (sec. 96). He thus tacks close to a standard Leibnizian line of attack and invokes the charge of unintelligibility. But the objection may be too hasty, given the rest of Wolff's philosophical theses. To be sure, when two bodies in relative motion make contact, we understand that one causes the other's change of motion (and vice versa). Still, it is far harder to grasp how such change comes about. Wolff ought to have acknowledged that. He knew from Leibniz that action by contact has its own mysteries. ${ }^{36}$ What is more, Wolff

${ }^{35}$ He states this requirement as a claim that the kinematic rules of collision can and should be derived a priori from metaphysical laws of motion; see Wolff 1737, sec. 303.

${ }^{36}$ In the late seventeenth century, impact was the paradigm of "communication of motion," the process whereby one body transfers velocity to another. Leibniz had long warned that, when thus conceived, impact is incoherent, hence unintelligible: it assumes the transfer of accidents (motion or velocity) between substances - a metaphysical absurdity. Having converted to Leibnizian "force" as the active principle of created substance, Wolff initially thought impact is a type of force transfer between bodies. In a private letter, Leibniz disabused him of that notion too: "you should know that forces do not migrate from one body into another" (vires non transire de corpore in corpus) (see Gerhardt 1860, 131). Evidently, the reason is that force is just as little transferable as motion, both being properties of substances. But then Wolff ought to explain what makes collision intelligible, given that our two most basic intuitions about it are metaphysically inconceivable. 
had previously admitted that we lack clear and distinct notions of his vis motrix and vis inertiae, the two forces that, in Wolff's metaphysical dynamics, are exerted by any two bodies in impact. ${ }^{37}$ This implies, however, that we also lack clear and distinct notions of interaction by contact. Thus, the very foundations of Wolffian doctrine entail that impact is ultimately unintelligible, and so it is hard to see why we must single out Newtonian gravity for opprobrium.

In sum, then, Wolff's doctrine of intelligibility, though it differs drastically from Newton's, is both too weak and too strong to support his polemic against Newtonian gravity. Wolff's official charge, however, was that distant action is impossible, an accusation that his prestige in Germany helped turn into the received consensus. It was against this charge of impossibility that a brilliant defender of Newton pushed back.

Over a decade after Wolff's condemnations in Cosmologia Generalis, Newtonian gravity found unexpected support from Daniel Bernoulli- to the dismay of his father Johann, who had bitterly fought Newtonianism under Leibniz's banner. At the Imperial Academy in St. Petersburg, Bernoulli had spoken up for Newton, gently with friends like Euler, firmly with Leibnizians like Bilfinger. ${ }^{38}$ He then found a subtle way to put Newton's enemies on the defensive. He did it obliquely, as an early aside in a 1746 paper where he set out to model magnetism "mechanically," based on the "Cartesian principle" that "in the world everything happens through matter and motion," that is, by contact action (Bernoulli 1752, 119). ${ }^{39}$ Though he relies on this principle in the paper, Bernoulli finds it insufficient and claims to have a reason for the "very reality" of another basic tenet, namely, "the mutual attraction of all matter." In nuce, his argument is this: without attractive force, mass would continually flow out of any finite volume, and hence, its density would decrease without limit. Consequently, matter could not form stable structures:

37 "We perceive the motive force of bodies only confusedly," because "motive force is a phenomenon," and the same holds for vis inertiae; see Wolff 1737, secs. 294-98. By "phenomenon', Wolff does not mean a mind-dependent entity or the semantic content of a representation, as Leibniz did, whom Wolff explicitly abjures. Rather, he means two things: (i) an entity presentable to the senses and (ii) an object or property that we can perceive only confusedly. He has two systematic reasons to deny we could ever have distinct knowledge of vis motrix and vis inertiae. First, these forces arise from the active and passive forces of "elements," or "physical monads," the ground-level entities of his metaphysics. But Wolff confesses that he cannot quite explain how this arising occurs (see Wolff 1730, sec. 795; Wolff 1737, sec. 294). Second, he admits that he does not know the nature of the basic forces in physical monads, or how they differ from each other (see Wolff 1737, sec. 294). It follows that he has no account of bodily forces (vis motrix and vis inertiae) that meets his own demands for genuine insight. Eo ipso, he cannot vindicate the claim that action by contact is eminently intelligible and, thus, unlike Newtonian gravity. For the intricacies of Wolff's notion of a phenomenon, see Campo 1938, 220.

38 On Daniel's polemic with Bilfinger at St. Petersburg, see Boss 1972, 108-11.

${ }^{39}$ By "Cartesian," Bernoulli means any adherent of the doctrine that all mechanical action is by contact - not any strict disciple of Descartes. In this sense, Leibniz's followers all count as Cartesians. 
if there were only matter and motion in the world, it seems the world could not subsist. This is because whatever motion we would conceive in matter - be it circular (as is that of ether vortices) or rectilinear (e.g. that of centripetal jets) or a motion of agitation (in which particles of matter collide, move away from one another or approach mutually) or indeed any other motion we may imagine - it is then certain that the matter which composed this Universe would always spread out, hence become ever more rarefied until it finally dissipates. This outcome is certain, based on laws of mechanics recognized by all. And the challenge it poses could not be defused by saying that the world is infinitely extended; for even then its lack of permanence will keep occurring. (Bernoulli 1752, 119)

But matter is stable, and thus, "its state of permanence consists in an equilibrium between matter's effort to spread out (due to its motion, of whatever kind it may be) and its mutual attraction" (Bernoulli 1752, 119). Hence, distant gravity must be a real and essential property of matter.

Such moves have come to be known as "balancing arguments," an inference-schema seeking to prove that for matter to have stable configurations, it must have a certain type of force so as to balance another kind of force already known to exist. Bernoulli's point is that attraction at a distance must be essential to matter because it is needed to balance the force responsible for rebound in elastic impact. To be sure, Bernoulli's argument is not conclusive (nor does he offer it as such); a good deal of its strength depends on factors left out of the argument, for example, initial conditions such as the distribution of masses and their initial velocities in the universe. ${ }^{40}$ Still, his thought strikingly presages the balancing arguments that Kant will employ to great effect, both in the early Physical Monadology and later, in the Critical period, so as to argue that attractive force is part of the essence of matter. ${ }^{41}$ Note, however, that Bernoulli and Kant advance conclusions that go beyond what Newton himself was willing to accept. Their balancing arguments infer that gravity is essential to matter, a view that Newton loathed: he took care to distinguish between the universal and essential properties of matter, and in the third edition of the Principia (1726), he affirmed that gravity was "universally established by experiments and astronomical observations" while demurring that he is "by no means affirming that gravity is essential to bodies" (cf. Newton 1999, 795). If we juxtapose Bernoulli's and Kant's defenses next to Maupertuis' 1732 resonating advocacy of gravitation as essential to matter, it turns out that key Enlightenment figures radicalized Newton's cautious stance on

\footnotetext{
${ }^{40}$ For a formal treatment of Bernoulli's set-up within the framework of classical gravitation theory, see Armellini 1950.

${ }_{41}$ An exquisite account of Kant's balancing argument in the 1786 Metaphysical Foundations of Natural Science is in Smith, forthcoming. See also Michael Friedman's contribution to this volume for an illuminating account of the connection between Kant's balancing argument and his treatment of quantity of matter.
} 
action at a distance even as they sought to show that Newtonianism was philosophically superior to the Leibnizian alternative. ${ }^{42}$

\section{GONCLUSION}

My brief treatment of the Wolffian reaction to the foundations of Newton's mechanics is admittedly more programmatic than conclusive. Much work still remains to be done in order to improve our understanding of the reception and impact of Newton's philosophy of mechanics in Enlightenment Europe. For instance, we should examine some genuine attempts to reconcile Leibnizianism and Newtonianism, such as those of Samuel König (1749) and Nicolas de Beguelin (1782). We should inquire into d'Alembert's and Euler's respective views on absolute space and action at a distance. And we must document how an alternative, Leibnizian mechanics built on vis viva grew at the hands of Hermann, Johann and Daniel Bernoulli, and König into a serious rival to Newton's theory.

Even with these issues lingering, what I have documented above offers a starting point and general framework for understanding the fierce opposition that Newton's foundations of mechanics met with from Continental thinkers swayed by Leibniz. The arguments I presented above indicate, in particular, why Wolff was particularly effective in slowing down the spread of Newtonianism in Germany. The philosophical rift between Newton and Leibniz, which had come to light during the latter's correspondence with Clarke, continued to color a good deal of the Leibnizians' reaction to the Principia. Led by Wolff, whom they acclaimed as praeceptor Germaniae, they continued to argue for a metaphysics of dynamics ultimately at odds with Newton's theory. Additionally, the Wolffians sharply diverged from Newton on the issue of intelligibility and the structure of physical explanation. It took nearly four decades for Newton's absolute space, laws of force, and gravitation theory to gain the upper hand. Thus, as a result of efforts by various Newtonians to re-argue the case for the Principia's conceptual foundations, around midcentury, Leibnizian philosophy of physics turns defensive, just as another threat begins to loom - the rise of Kant.

Moreover, my case study in this paper gestures toward an important philosophical lesson about historical episodes of theory change. Others before me have expressed reservations about Thomas Kuhn's famous account of how revolutionary science turns "normal" (Kuhn 1962, 32-40), but my results here give fresh cogency to their misgivings. In the case of Newton's

42 Maupertuis' defense of Newtonian gravity as an essential property of matter is skillfully examined in Downing 2012, 280-98. 
Principia, there was not, as Kuhn's story would suggest, a revolutionary outburst of a new paradigm followed by patient, collective work on its details. To become normal science on the Continent, it in fact took Newton's mechanics many decades. As I have shown, this was in good part because of deep, hard problems surrounding the philosophical foundations of his theory rather than its puzzle-solving power. Newton's Leibnizian opponents believed that acceptance of his mechanics was neither inevitable - for the Principia had not shaken their faith in an alternative, Leibnizian dynamics - nor warranted, as long as Newton's theory lacked foundations compatible with their metaphysics and epistemology. This historical episode should prompt us to reconsider how new scientific theories become accepted: is it on their problem-solving strength alone, or do philosophical issues also have a role to play? The fate of Newton's mechanics in post-Leibnizian Germany suggests they do, indeed. ${ }^{43}$

\section{REFERENCES}

Alexander, H. G. 1970. The Leibniz-Clarke correspondence. Manchester: Manchester University Press.

Anonymous. 1751. Review of Histoire de l'Académie Royale des Sciences et des Belles Lettres de Berlin pour l'année 1748 [History of the Royal Academy of Sciences and letters in Berlin for the year 1748]. Nova Acta Eruditorum, 61-77.

Armellini, G. 1950. L'espansione dell'Universo nella meccanica classica [The expansion of the universe according to classical mechanics]. Atti della Accademia Nazionale dei Lincei. Rendiconti, Classe di Science fisiche, matematiche e naturali, 8: 15-23.

Barber, W. H. 1955. Leibniz in France: From Arnauld to Voltaire. Oxford: Clarendon Press.

Beguelin, N. de. 1782. Versuch einer Vereinigung der Leibnitzschen Metaphysik und der Newtonschen Physik, aus welcher die Erklärung der allgemeinsten und wichtigsten Naturerscheinungen fliesst [An attempt to unify the Leibnizian metaphysics and Newtonian physics: From which the explanation of the most general and important natural phenomena follows]. Berlin: Meyer.

Bernoulli, D. 1752. Nouveaux Principes de Méchanique et de Physique, tendans à expliquer la Nature \& les Propriétés de l'Aiman [New principles of mechanics and physics, with a view to explaining the nature and properties of magnets]. Recueil des pièces qui ont remporté des prix de l'Académie royale des sciences 5: 117-44. Paris: Martin, Coignard, Guerin, Jombert. Also in Die Werke von Daniel Bernoulli, vol. 7, ed. P. Radelet-de Grave, 113-36. Basel: Birkhäuser.

Borelli, G. A. 1667. De Vi Percussionis [On the force of percussion]. Bologna: J. Monti.

Boss, V. 1972. Newton and Russia: The early influence, 1698-1796. Cambridge, MA: Harvard University Press.

Brackenridge, J. B. 1995. The key to Newton's dynamics: The Kepler problem and the Principia. Berkeley: University of California Press.

${ }^{43}$ I thank Mary Domski for invaluable advice, patient guidance, constructive suggestions, and insightful comments as I wrote this paper. I am grateful to two anonymous referees for their penetrating comments and subtle observations on a previous draft. 
Burkhäuser, N. 1771. Institutiones Metaphysicae, Pars I: de Ente. [Elements of metaphysics, part 1: On being]. Würzburg: Goebhardt.

Calinger, R. S. 1969. The Newtonian-Wolffian controversy: 1740-1759. Fournal of the History of Ideas 30: 319-30.

Campo, M. 1938. Cristiano Wolff e il razionalismo precritico [Christian Wolff and pre-Critical rationalism]. 2 vols. Milan: Vita e Pensiero.

Cannon, J. T., and S. Dostrovsky. 1981. The evolution of dynamics: Vibration theory from 1687 to 1742. New York: Springer.

Descartes, R. 1983. Principles of philosophy. Trans. V. Rodger Miller and R. P. Miller. Dordrecht: Reidel.

Döring, H. 1831. Die gelehrten Theologen Deutschlands im achtzehnten und neunzehnten Fahrhundert [The learned theologians of Germany in the eighteenth and nineteenth centuries]. Vol. 1. Neustadt: J. K. G. Wagner.

Downing, L. 2012. Maupertuis on attraction as an inherent property of matter. In Interpreting Newton, ed. E. Schliesser and A. Janiak, 280-98. Cambridge: Cambridge University Press.

Droysen, H. 1909. Die Marquise du Châtelet, Voltaire und der Philosoph Christian Wolff. Zeitschrift fü französische Sprache und Literatur 35: 226-48.

Du Châtelet, G. E. 1742. Institutions physiques [Elements of physics]. Vol. 1. Amsterdam: n.p.

Ducheyne, S. 2011. The main business of natural philosophy: Isaac Newton's natural-philosophical methodology. Dordrecht: Springer.

Euler, L. 1748. Réfléxions sur l'Espace et le Tems [Thoughts on space and time]. In Histoire de l'Académie Royale des Sciences et Belles Lettres (1748), 324-33. Berlin: Haude and Spenner.

-1763. Vernünftige Gedanken von dem Raume, dem Orth, der Dauer und der Zeit [Rational thoughts on space, place, duration and time], ed. F. E. Boysen, Quedlinburg: Schwan.

Fuss, P. H. 1843. Correspondance mathématique et physique de quelques célèbres géomètres du XVIIIème siècle [Mathematical and physical letters of some famous eighteenth century geometers]. Vol. 1. St Petersburg: Imprimerie de l'Académie impériale des sciences.

Gerhardt, C. I., ed. 1860. Briefwechsel zwischen Leibniz und Christian Wolff [Correspondence between Leibniz and Christian Wolff. Supplement-Band zu Leibnizens Gesammelte Werke. Halle: H. W. Schmidt.

Gottsched, J. Ch. 1733. Erste Gründe der gesammten Weltweisheit: erster, theoretischer Teil [Basic principles of the entire philosophy: Part I, Theoretical philosophy]. Leipzig: Breitkopf.

Guerlac, H. 1981. Newton on the Continent. Ithaca, NY: Cornell University Press.

Halley, E. 1720. Considerations on the change of the latitude of some of the principal fixt stars. Philosophical Transactions 30: 736-38.

Hanov, M. Chr. 1762. Philosophia Naturalis, sive Physica Dogmatica [Natural philosophy: or, dogmatic physics]. Vol. 1. Halle: Renger.

Henry, J. 2011. Gravity and De Gravitatione: The development of Newton's ideas on action at a distance. Studies in History and Philosophy of Science 42: 11-27.

Hermann, J. 1716. Phoronomia, sive de Viribus et Motibus Corporum solidorum et fluidorum libri duo [Phoronomy: or, a Treatise on the forces and motions of solid and fluid bodies, in two books]. Amsterdam: Wetsten Bros. 
Hirsching, F. K. G. 1812. Historisch-literarisches Handbuch berühmter und denkwürdigen Personen, welche in dem 18. Fahrhunderte gestorben sind [Historical-literary dictionary of famous and memorable persons who died in the 18th century]. Vol. 15.3. Leipzig: Schwickert.

Janiak, A. 2008. Newton as philosopher. Cambridge: Cambridge University Press.

König, S. 1749. Oratio inauguralis, de optimis Wolfiana et Newtoniana, philosophandi methodis: earumque amico consensu [An inaugural lecture on the two best methods to philosophize, Wolffian and Newtonian: And on their agreement]. Leuven and Franeker: G. Coulon.

Kuhn, Th. 1962. The structure of scientific revolutions. Chicago: Chicago University Press.

Leibniz, G. W. 1698. De Ipsa Natura [On nature itself]. In G. W. Leibniz: Philosophical texts, ed. R. Francks and R. S. Woolhouse, 209-22. Oxford: Oxford University Press, 1998.

LeSeur, Th., and Fr. Jacquier. 1739. Philosophice naturalis principia mathematica, auctore Isaaco Newtono [The mathematical principles of natural philosophy, by Isaac Newton]. Vol. 1. [n.p.]: Barrillot.

Maltese, G. 1992. La Storia di "F=ma". La seconda legge del moto nel XVIII secolo [The story of $F=m a:$ the Second Law in the eighteenth century]. Florence: Olschki.

Mariotte, E. 1740. Oeuvres de M. Mariotte [The works of Mariotte], nouvelle edition, vol. 1. The Hague: J. Neaulme.

Miller, D. M. 2009. Qualities, properties and laws in Newton's induction. Philosophy of Science 76: 1052-63.

Mühlpfordt, G. 1986. Zur Differenzierung und Wirkung der Wolffschen Schule ab 1735 [On the differentiation and impact of the Wolffian school from 1735 onward]. In Christian Wolff 1679-1754: Interpretationen zu seiner Philosophie und deren Wirkung, ed. W. Schneiders, 237-53. Hamburg: Felix Meiner.

Nauenberg, M. 2010. The early application of the calculus to the inverse square force problem. Archive for History of Exact Sciences 64: 269-300.

Newton, I. 1999. The Principia. Trans. I. B. Cohen and A. Whitman. Berkeley: University of California Press.

Robinet, A. 1991. La conquête de la chaire de mathématiques de Padoue par les leibniziens [The Leibnizians' conquest of the mathematics chair at Padua]. Revue d'histoire des sciences 44: 181-201.

Rynasiewicz, R. 1995. By their properties, causes and effects: Newton's Scholium on time, space, place and motion. Studies in History and Philosophy of Science 26: 133-53, 295-321.

. 2000. On the distinction between absolute and relative motion. Philosophy of Science 67: 70-93.

Sharpe, G. 1744. A defence of the late Dr. Samuel Clarke against the Reply of Sieur Lewis-Philip Thummig in favour of Mr Leibnitz, with that Reply, in French and English. London: Knapton.

Smith, S. Forthcoming. Does Kant have a pre-Newtonian picture of force in the balance argument? An account of how the balance argument works. Studies in History and Philosophy of Science.

Speiser, A. 1960. Einleitung [Introduction]. In Leonhardi Euleri Opera Omnia, III.1. Zürich: Orell Füssli.

Stan, M. 2011. Rebellious Wolffian: Kant's philosophy of mechanics in 1758. In Rethinking Kant, vol. 3, ed. O. Thorndike, 158-79. Newcastle upon Tyne: Cambridge Scholars. - Forthcoming. Kant's third law of mechanics: The long shadow of Leibniz. Studies in History and Philosophy of Science. 
Stiebritz,J. Fr. 1744. Philosophiae Wolfianae Contractae [The Wolffian philosophy, abridged]. Vol. 1. Halle: Renger.

Thümmig, L. Ph. 1735. Institutiones Philosophiae Wolfianae [Elements of Wolffian philosophy]. Frankfurt: Renger.

Watkins, E. 1997. The Laws of Motion from Newton to Kant. Perspectives on Science 5: $311-48$.

Winckler, J. H. 1735. Institutiones Philosophiae Wolfianae, Pars I Contemplativa [Elements of Wolffian philosophy: Part I, contemplative philosophy]. Leipzig: Fritsch.

[Wolff, Chr.]. 1717. Collectio Schedarum per quas Vir Illustris Leibnitius et D. Clarkius Anno 1715 \& 1716 de principiis quibusdam Philosophiae et Religionis naturalis disputarunt [A collection of letters whereby the distinguished Leibniz and Mr. Clarke debated in the years 1715 and 1716 on certain principles of philosophy and natural religion]. Acta Eruditorum, 440-47.

Wolff, Chr. 1730. Philosophia prima, sive Ontologia [First philosophy: or, Ontology]. Frankfurt: Renger.

1737. Cosmologia Generalis [General cosmology]. 2nd ed. Frankfurt: Renger. 